\title{
CARACTERIZAÇÃO MICROBIOLÓGICA DE POLPAS DE QUATRO FRU- TAS REGIONAIS COMERCIALIZADAS NAS FEIRAS DE SÃO LUÍS / MA*
}

MICROBIOLOGICAL CHARACTERIZATION OF FOUR REGIONAL FRUIT PULP SOLD IN MARKET PLACES OF SAN LUIS/MA

CARACTERIZACIÓN MICROBIOLÓGICA DE PULPAS DE CUATRO FRUTAS REGIONALES CORMECIALIZADAS EN LAS FERIAS DE SÃO LUÍS/MA.

Wellyandra Costa dos Santos Graduanda em Ciências Biológicas pela Universidade Federal do Maranhão/UFMA

Adenilde Ribeiro Nascimento Doutora em Ciências dos Alimentos pela Universidade Federal de Lavras

RESUMO: O objetivo da pesquisa foi avaliar as características higiênico-sanitárias de polpas de quatro frutas regionais comercializadas nas feiras de São Luís - MA, tais como: Acerola, Bacuri, Cupuaçu, Goia-ba. Determinou-se o Número Mais Provável (NMP/g) de coliformes a $45^{\circ} \mathrm{C}$, Pesquisa de Salmonella $\mathrm{sp}$. e contagem de Bolores e Leveduras. As análises foram realizadas de acordo com as técnicas recomen-dadas pelo Compendium of Methods for the Microbiological Examination of Foods - APHA (2001). Das amostras das polpas de Acerola, Bacuri, Cupuaçu, Goiaba $10 \%$ estavam contaminadas por coliformes a $45^{\circ} \mathrm{C}$, com valores variando entre 240 a $2400 \mathrm{NMP} / \mathrm{g}$, estando impróprias para o consumo segundo os padrões de qualidade exigidos pela ANVISA/ 2001 (102 NMP/g). As amostras analisadas não apresenta-ram presença de Salmonella sp. Todas as amostras analisadas estavam fora dos padrões de qualidade, apresentando altas contagens de bolores e leveduras.

Palavras-chave: Polpas de frutas. Coliformes a 45ํㅡ. Bolores e leveduras. Qualidade microbiológica.

ABSTRACT: The objective of this research was to evaluate the sanitary hygienic characteristics of four regional fruit pulp sold at fairs in São Luís-MA, such as: Bacuri, Cupuaçu, Acerola, Guava. Determining the most probable number (MPN) of coliform to $45^{\circ} \mathrm{C}$, search of Salmonella sp. and enumeration of yeasts and molds. The analyses were carried out in accordance with the techniques recommended by the Com-pendium of Methods for the Microbiological Examination of Foods - APHA (2001). Samples of Acerola pulp, Bacuri, Cupuaçu, guava $10 \%$ were contaminated with coliforms to $45^{\circ} \mathrm{C}$, with values ranging from 240 to $2400 \mathrm{MPN} / \mathrm{g}$ being unfit for consumption according to the quality standards required by ANVISA 2001 (102 MPN/g). The samples analyzed did not show the presence of Salmonella sp. All samples analy-sed were outside the quality standards featuring high counts of mold and yeasts.

KEYWORDS: Fruit Pulps. Coliforms to $45^{\circ} \mathrm{C}$. Yeasts and molds. Microbiological quality.

\footnotetext{
* Trabalho premiado durante o XXV Encontro do SEMIC, realizado na UFMA, entre os dias 18 a 22 de novembro de 2013. Artigo recebido em fevereiro de 2014

Aprovado abril de 2014
} 
RESUMEN: El objetivo de la investigación fue evaluar las características higiénico-sanitarias de pulpas de cuatro frutas regionales comercializadas en las ferias de São Luís-MA tales como: Acerola, Bacuri, Cupuaçu, Guayaba. Contando con el numero más probable (NMP/g) de coliformes $45^{\circ} \mathrm{C}$, Busquedas de Salmonella sp., y recuento de mohos y levaduras Los análisis fueron realizados en acuerdo con las técni-cas recomendadas por el Compendium of Methods for the Microbiological Examination of Foods - APHA

(2001). De las muestras de pulpas como Acerola, Bacuri, Cupuaçu y Guayaba, 10\% estaban contaminadas por coliformes fecales a $45^{\circ} \mathrm{C}$, con valores variando entre 240 a $2400 \mathrm{NMP} / \mathrm{g}$ estando impropias para el consumo según los modelos de calidad exigidos por la ANVISA/ 2001 (102 NMP/g). Las muestras analizadas no presentaron la presencia de Salmonella $s p$. Todas las muestras analizadas no seguían los modelos de calidad presentando altas enumeraciones de mohos y levaduras

PALABRAS CLAVE: : Pulpas de frutas. Coliformes a $45^{\circ} \mathrm{C}$. Mohos y Levaduras. Calidad microbiológica. 


\section{1 | Introdução}

As frutas são utilizadas como matéria-prima para a elaboração de diferentes produtos alimentícios, dentre os quais sucos, refrescos, geleias, sorvetes e doces (SANTOS et al., 2004). Segundo o Ministério da Agricultura, Pecuária e Abastecimento, a polpa de fruta pode ser definida como "produto" não fermentado, não concentrado, não diluído, obtido pelo esmagamento de frutas polposas mediante processo tecnológico adequado, com teor mínimo de sólidos totais provenientes da parte comestível do fruto (BRASIL, 2000).

A comercialização de polpas de frutas é realizada por ambulantes e os locais em que são comercializadas podem influenciar diretamente na qualidade do produto. As polpas de frutas são consideradas alimentos de rua, devido, em geral, ao baixo preço, familiaridade, conveniência e fácil acesso. Sua oferta varia conforme a riqueza cultural da população (HANASHIRO et al., 2002).

A comercialização de produtos derivados de frutas tem crescido em todo o mundo (BRUNINI; DURIGAN; OLIVEIRA, 2002), sendo que a demanda apresenta tendência de crescimento devido às suas características organolépticas e vantagens à saúde. A alta perecibilidade dos frutos é responsável por perdas significativas, o que tem impulsionado o desenvolvimento de processos tecnológicos, destacando-se a produção de polpas de frutas congeladas (SALGADO; GUERRA; MELO, 1999). Devido a isso, as polpas de frutas congeladas surgem como uma excelente alternativa de garantia de aproveitamento do excedente, de melhores condições de manuseio, de armazenamento, de transporte e, acima de tudo, da oferta permanente desses frutos para 0 mercado consumidor (ARRUDA et al., 2006).

A deterioração dos alimentos caracteriza-se por diversos tipos de alteração de ordem química, física ou microbiológica, que resultam na perda progressiva dos níveis de qualidade do produto. Todos os alimentos sofrem graus variados de deterioração durante sua estocagem, que podem comprometer a segurança alimentar do consumidor (EMPRESA BRASILEIRA DE PESQUISA AGROPÉCUÁRIA, 2013).

A capacidade de crescimento e de sobrevivência dos micro-organismos patogênicos nos alimentos depende não somente das características físicas e nutricionais desses alimentos, como também de um conjunto de fatores extrínsecos e intrínsecos a eles, tais como: temperatura, $\mathrm{pH}$, atividade da água e potencial redox, cada um dos quais podendo ser manipulado conveniente-mente, de modo a impedir a contaminação e o crescimento de micro-organismos patogênicos (PINTO, 1996).

Neste contexto, esta pesquisa teve por objetivo analisar as condições higiênico-sanitárias de polpas de quatro frutas regionais: Acerola, Bacuri, Cupuaçu e Goiaba, comercializadas nas feiras de São Luís - MA. Determinou-se o Número Mais Provável (NMP) de coliformes a $45^{\circ} \mathrm{C}$, pesquisa de Salmonella sp., pesquisando Salmonella sp. e realizou-se a contagem de Bolores e Leveduras.

\section{2 | Metodologia}

'As amostras foram coletadas no município de São de Luís/MA, em diversas feiras livres e mercados. Todas as análises foram realizadas conforme as técnicas recomendadas pelo Compendium of Methods for the Microbiological Examination of Foods - APHA (VANDERZANT; SPLITTSTOESSER, 2001).

Para a pesquisa de coliformes a $45^{\circ} \mathrm{C}$, utilizou-se a técnica dos tubos múltiplos. Inicialmente, $25 \mathrm{~g}$ da amostra foram diluídas em $225 \mathrm{~mL}$ de solução salina estéril a $0,85 \%$ de $\mathrm{NaCl}$, de modo a obter-se a diluição $10^{-1}$. Posteriormente foram realizadas diluições sucessivas, $10^{-2}$ e $10^{-3}$. Alíquotas de $1 \mathrm{~mL}$ de cada diluição foram inoculados em série de três tubos, contendo o Caldo Lauril Sulfato Triptose com incubação a $35^{\circ} \mathrm{C}$ por 48 horas. Após o período de incubação, os tubos positivos foram repicados Caldo $\mathrm{E}$. C. incubados a $45^{\circ} \mathrm{C}$. 
Os tubos de Caldo E.C positivos foram plaqueados no Ágar EMB (Eosina Azul de Metileno) e, após o período de incubação, as colônias típicas de Escherichia coli foram isoladas e identifica-das através de testes bioquímicos.

Para a pesquisa de Salmonella, retirou-se $25 \mathrm{~g}$ da polpa para $225 \mathrm{~mL}$ de Água peptonada tamponada, com incubação a $37^{\circ} \mathrm{C}$ por 24 horas. Em seguida, retirou-se $1 \mathrm{~mL}$ para o caldo Tetrationato por 24 horas a $35^{\circ} \mathrm{C}$. Logo após, foram semeadas em Agar Hecktoen e Agar Bismuto e incubadas por $35^{\circ} \mathrm{C}$ por 24 horas. As colônias características foram isoladas em meio TSI e identificadas bioquimicamente.

As contagens de Bolores e Leveduras foram feitas com o uso da técnica Pour-plate usandomeio Ágar batata acidificado e incubados a $25^{\circ} \mathrm{C}$ por 5 dias onde foram realizadas as contagens no contador de colônias.

\section{3 | Resultados e discussão}

Tabela 1 - Distribuição do Número mais Provável de Coliformes a 45ํㅡ (NMP/mL), contagem de Bolores e Levedu-ras (UFC/mL) e pesquisa de Salmonella $s p$

\begin{tabular}{c|c|c|c|l}
\hline Alimentos & $\begin{array}{l}\mathbf{N}^{\mathbf{0}} \text { de } \\
\text { amostras } \\
\text { analisadas }\end{array}$ & $\begin{array}{l}\text { \% de } \\
\text { contaminação } \\
\text { por Coliformes } \\
\mathbf{a} 45^{\circ} \mathbf{C} \text { NMP/g }\end{array}$ & $\begin{array}{c}\text { *Bolores } \\
\text { e } \\
\text { Leveduras } \\
\text { UFC/g }\end{array}$ & $\begin{array}{c}\text { Pesquisa } \\
\text { de } \\
\text { Salmonella }\end{array}$ \\
\hline Polpa de Acerola & 14 & 14,3 & $\begin{array}{c}6,4 \times 10^{4} \\
\mathrm{e} \\
3,28 \times 10^{7}\end{array}$ & $\begin{array}{l}\text { Ausência } \\
\text { em 25g }\end{array}$ \\
\hline Polpa de Bacuri & 12 & 0 & $\begin{array}{c}3 \times 10^{4} \\
\mathrm{e}\end{array}$ & $\begin{array}{l}\text { Ausência } \\
\text { em 25g }\end{array}$ \\
\hline $\begin{array}{c}\text { Polpa de } \\
\text { Cupuaçu }\end{array}$ & 12 & $8,8 \times 10^{7}$ & $\begin{array}{c}4 \times 10^{4} \\
\mathrm{e}\end{array}$ & $\begin{array}{l}\text { Ausência } \\
\text { em 25g }\end{array}$ \\
\hline Polpa de Goiaba & 15 & 46,7 & $\begin{array}{c}1,40 \times 10^{4} \\
\mathrm{e}\end{array}$ & $\begin{array}{l}\text { Ausência } \\
\text { em 25g }\end{array}$ \\
\hline
\end{tabular}

*Padrão da ANVISA: $100 \mathrm{NMP} / \mathrm{g} / \mathrm{mL}$ (coliformes)

*Não apresenta padrão na RDC 12 de 02 de janeiro de 2001 Fonte:

AGÊNCIA NACIONAL DE VIGILÂNCIA SANITÁRIA (2001)

Das 14 amostras de polpas de acerola analisadas, 12 não apresentaram coliformes a $45^{\circ} \mathrm{C}$, estando esse quesito dentro dos padrões de qualidade exigidos pela Agência Nacional de Vigilância Sanitária (2001). A partir da comparação dos resultados obtidos nesta pesquisa com os resultados do trabalho de Nascimento et al. (2006), pode-se verificar que os níveis de contaminação por coliformes a 45ㄷ em polpas de fruta comercializadas na cidade de São Luís são mínimos ou quase inexistentes. Tal ausência, ou presença em pequena quantidade, de alguns micro-organismos em sucos e/ou polpas de frutas pode ser explicado devido à presença de substâncias antimicrobianas naturais - como óleos essenciais, compostos fenólicos, ácido benzoico, ácido sórbico e outros ácidos orgânicos de cadeia curta (GELDREICH et al., 1962).

Entretanto, a análise de polpas de fruta ainda se faz necessária, visto que outros micro-orga- 
nismos podem crescer, mesmo diante da presença desses compostos antimicrobianos, como verificado nesta pesquisa, onde as contagens de Bolores e Leveduras apresentaram elevados valores destes micro-organismos. Resultados similares foram também encontrados no trabalho realizado por Nascimento et al. (2006), o que pode representar um forte indício de contaminação da matéria-prima ou condições de armazenamento inadequadas. A presença desses micro-or-ganismos nos alimentos pode representar perigo à saúde pública em razão da produção de micotoxinas pelos bolores, sendo, portanto, necessário um constante monitoramento das suas condições microbiológicas.

Segundo os resultados apresentados nesta pesquisa, 100\% das amostras de polpas de bacuri analisadas estavam dentro do padrão de qualidade exigidos na RDC $\mathrm{n} \div \mathbf{1 2}$, de 02 de Janeiro de 2001 (AGÊNCIA NACIONAL DE VIGILÂNCIA SANITÁRIA, 2001). Estavam dentro do padrão para coliformes a $45^{\circ} \mathrm{C}$ e ausência de Salmonella. No que se refere a Bolores e Leveduras, a legislação RDC ํำ12, de 02 de Janeiro de 2001 não apresenta padrão. Na instrução normativa nº

1, de 7 de Janeiro de 2000, foi aprovado o Regulamento Técnico geral para fixação dos Padrões de Identidade e Qualidade para polpas de fruta, incluindo a contagem de Bolores e Leveduras para esta classe de produtos, fixando limites máximos para polpa in natura $\left(5,0 \times 10^{3} / \mathrm{g}\right.$ ou $\left.\mathrm{mL}\right)$. (BRASIL, 2000). Todas as amostras apresentaram altas concentrações de Bolores e Leveduras em $25 \mathrm{~g}$ da amostra, em desacordo com a instrução nํㅜ 1, de 7 de Janeiro de 2000.

Segundo os resultados obtidos das análises de polpas de cupuaçu para análises de coliformes a $45^{\circ} \mathrm{C}$ apenas 1 amostra estava fora do padrão exigido pela ANVISA. No que se refere a Bolores e Leveduras, todas as amostras estavam fora do padrão, apresentando valores para contagem entre $4 \times 10^{4}$ e $1,28 \times 107$ UFC.g ${ }^{-1}$. Não foi detectada presença de Salmonella em nenhuma das amostras analisadas.

Segundo Santos, Coelho e Carreiro (2008), ao analisarem oitenta e oito amostras, observou-se que $(89,8 \%)$ apresentaram contaminação por bolores e leveduras, sendo que as contagens variaram de $<10$ até $6,2 \times 104$ UFC. $g^{-1}$. Esses valores são semelhantes aos apresentados nesta pesquisa, Santos cita que provavelmente os valores elevados de Bolores e Leveduras podem ser parcialmente atribuídos, ao elevado teor de carboidratos normalmente presentes nas polpas de frutas, além do caráter ácido das mesmas.

Embora o baixo $\mathrm{pH}$ favoreça o desenvolvimento desses micro-organismos, não houve relação direta entre o $\mathrm{pH}$ e uma maior ou menor contagem de Bolores e Leveduras nas diferentes polpas. Dentre as polpas que apresentaram contaminação por Bolores e Leveduras, $29(29,6 \%)$ não se enquadraram nos padrões estabelecidos pela Instrução Normativa 12 de 10/09/99, a qual preco-niza um máximo de $5 \times 10^{3}$ UFC.g ${ }^{-1}$.

Segundo os resultados obtidos nesta pesquisa, das 15 amostras de polpas de goiaba analisadas, ou seja, 07 (46,66\%) apresentaram coliformes a 45ํㅡ, com valores entre 290 a 2400 NMP, indicando provavelmente falhas na manipulação, estando fora dos padrões de qualidade exigidos pela Agência Nacional de Vigilância Sanitária (2001). Os valores referentes a Bolores

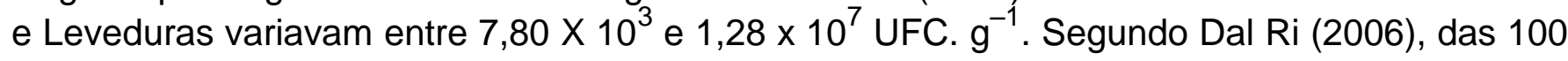
amostras analisadas, $78 \%$ estavam contaminadas por Bolores e Leveduras com valores encontrados acima do permitido pelo MAPA (2000). Já Santos, Coelho e Carreiro (2008), nos seus estudos, 70,4\% das amostras apresentaram-se dentro dos padrões microbiológicos para Bolores e Leveduras e apenas duas amostras em desacordo com relação a coliformes a 45ㄷ․

De acordo com Pereira et al. (2006), os resultados referentes a Bolores e Leveduras nas polpas de goiaba analisadas variavam entre $<1,0 \times 10$ a $2,6 \times 10^{4}$ UFC. $g^{-1}$, resultados semelhantes aos encontrados nesta pesquisa que nos mostram que as elevadas contagens desses micro--organismos, associadas à presença de bactérias do grupo coliformes, reforçam a hipótese de processamento inadequado e/ou recontaminação pós-processamento.

Segundo Franco e Landcraf (2009), o crescimento de Bolores e Leveduras é mais lento do 
que o de bactérias em alimentos de baixa acidez e com alta atividade de água, porém em alimentos ácidos e de baixa atividade de água, o crescimento de fungos é maior, provocando deterioração principalmente em frutas frescas, vegetais e cereais. São também responsáveis pela deterioração de sucos de frutas, queijos, alimentos congelados, desidratados e em conserva, quando armazenados em condições inadequadas.

\section{4 | Considerações finais}

A avaliação higiênico-sanitária das polpas de fruta analisadas revelou que $10 \%$ das amostras estavam em desacordo com o padrão para coliformes a $45^{\circ} \mathrm{C}$ e $100 \%$ apresentaram elevadas contagens de Bolores e leveduras. Não foi detectada a presença de Salmonella $s p$. em nenhuma das amostras.

Sob o ponto de vista sanitário, as polpas de fruta comercializadas nas feiras, ou seja, todas as polpas estudadas nesta pesquisa, estão impróprias para o consumo, por apresentarem condições higiênicas insatisfatórias.

Recomenda-se, portanto, a aplicação mais efetiva dos princípios de higiene e sanitização na produção, visando oferecer produtos que garantam a segurança, evitando, assim, riscos de toxinose alimentar.

\section{Agradecimentos}

Agradecemos ao PIBIC-UFMA por incentivar a pesquisa realizada.

Agradecemos a todos os técnicos e colaboradores do Programa de Controle de Qualidade de Água e Alimentos - PCQA. 


\section{Referências}

ARRUDA, M. G. P. et al. Incidência de fungos em polpas de cajá produzidas no município de Fortaleza: uma análise comparativa entre os métodos convencional e simplate. Higiene Alimentar, v. 20, n. 141, p. 94-97, 2006.

\section{AGÊNCIA NACIONAL DE VIGILÂNCIA SANITÁRIA.} RDC № 12, DE 2 DE JANEIRO DE 2001. Brasília, DF, 2001. Disponível em: <http://portal.anvisa.gov. br/wps/wcm/connect/a47bab8047458b909541d53fbc4c6735/RDC_12_2001.pdf?MOD=AJPERES>. Acesso em: 25 fev. 2014.

EMPRESA BRASILEIRA DE PESQUISA AGROPECUÁRIA. Livro apresenta fundamentos da estabilida-de de alimentos para garantir mais tempo de vida e estocagem. Brasília, DF, 2013 Disponível em: <http:// www.embrapa.br/embrapa/imprensa/noticias/2013/ janeiro/2a-semana/livro-apresenta-fundamentos-da-estabilidade-de-alimentos-para-garantir-mais-tempo-de-vida-e-estocagem>. Acesso: 20 fev. 2014.

BRASIL. Ministério da Agricultura, Pecuária e Abastecimento. Instrução normativa n. 01 , de 7 de janeiro de 2000. Aprova padrões de identidade e qualidade para polpas de frutas. Diário Oficial [da] República Federativa do Brasil, Brasília, 10 jan. 2000. Seção 1, p. 54.

BRUNINI, M. A.; DURIGAN, J. F.; OLIVEIRA, A. L. Avaliações das alterações em polpa de manga 'Tommy-Atkins' congelada. Revista Brasileira de Fru-ticultura, Jaboticabal, v. 24, n. 3, dez. 2002.

DAL RI, E. S. Avaliação do processo produtivo e da qualidade de polpas de frutas comercializadas em Boa Vista/RR. 2006. Dissertação (Mestrado em Recursos Naturais) - Universidade Federal de Roraima, Boa Vista, 2006.

FRANCO, B. D. G. M.; LANDCRAF, U. Microbiologia dos alimentos. São Paulo: Atheneu, 2008.
GELDREICH, E.E. et al. The fecal coli- aerogenes flora of soils from various geographical areas. J. Appl. Bacteriol., v. 25, p. 87-93, Apr. 1962.

HANASHIRO, A. et al. Qualidade higiênico-sanitária de alimentos de rua: populares versus orientais comercializados em São Paulo. [S.I.:s.n.], 2002.

NASCIMENTO, A. R. et al. Incidência de micro-organismos contaminantes em polpas de frutas comercializadas in natura em feiras livres da cidade de São Luís/Ma. B. CEPPA, Curitiba, v. 24, n. 1, jan./jun. 2006.

PEREIRA, J. M. A. T. K. et al. Avaliação da qualidade físico-química, microbiológica e microscópica de polpas de frutas congeladas comercializadas na cidade de Viçosa-Mg. Alim. Nutr., Araraquara, Araraquara, v.17, n.4, p.437-442, out./dez. 2006.

PINTO, A. D. M. Doenças de origem microbiana transmitidas pelos alimentos. 1996. Disponível em: <http://www.ipv.pt/millenium/ect4_1.htm>. Acesso em: 18 mar. 2013.

SALGADO, S. M.; GUERRA, N. B.; MELO FILHO, A. $B$. Polpa de fruta congelada: efeito do processamen-to sobre o conteúdo de fibra alimentar. Rev. Nutr., Campinas, v. 12, n. 3, p. 303-308, set./dez. 1999.

SANTOS, C. A. do A.; COELHO, A. F. S.; CARREIRO S. C. Avaliação microbiológica de polpas de frutas congeladas. Rev. Ciência e Tecnologia de Alimentos, Campinas, v. 28, n. 4, p. 913-915, out./dez. 2008.

SANTOS, F. A. et al. Análise qualitativa de polpas congeladas de frutas, produzidas pelo SUFRUTS, MA. Revista Higiene Alimentar, São Paulo, v.18, n. 119, p.18-22, abr. 2004.

VANDERZANT, C.; SPLITTSTOESSER, D. F. Compendium of methods for the microbiological examination of foods. Washington, DC: APHA, 2001, 1219p. 